\title{
CLUBHOUSE: DETERMINING THE MOST TALKED ABOUT TOPICS AND THEIR EFFECT ON THE PLATFORM'S POPULARITY
}

\author{
Luka Skeledzija and Eva Skeledzija \\ University of Ljubljana, Slovenia
}

\begin{abstract}
In early 2021, a new mobile app called "Clubhouse: drop-in audio" became extremely popular among internet users. This paper aims to give some insight into what topics are discussed on Clubhouse, what makes Clubhouse (and potentially other drop-in audio platforms) so appealing and what helped it acquire millions of users in a matter of weeks despite an invite-only registration system. It was determined through research that the 3 most popular topics on Clubhouse are all business related and that Clubhouse users tend to offer free high-value business advice to other entrepreneurs. Clubhouse's new media format was reported to be very authentic, which people from other industries are starting to take notice of.
\end{abstract}

\section{KEYWORDS}

Clubhouse, Business, Entrepreneurship, Mobile App, Drop-In Audio

\section{INTRODUCTION}

In early 2021, a new mobile app called "Clubhouse: drop-in audio" became extremely popular among internet users. In fact, it grew from 1.500 users in March 2020 (mainly from Silicon Valley) to more than 10.000.000 users as of February 2021 (Statista, 2021). The app offers the ability to create, listen and participate in the so-called drop-in audio rooms, where debates and interviews on different topics are taking place every day. This new kind of social media network became so interesting, that as of May 2021 there are more than 6 Clubhouse clones in the works by big technology companies (Instagram Audio Rooms, Telegram Voice Chat 2.0, LinkedIn Live Audio Rooms, Twitter Spaces, Spotify's Locker Room Talk, Discord Stage Channels, Facebook Audio Rooms) (Awa-Abuon, 2021). Similarly, Clubhouse's parent0020company, Alpha Exploration Co., is currently valued at over 1 billion USD (Culliford, 2021).

This paper aims to give some insight into what topics are discussed on Clubhouse, what makes Clubhouse (and potentially other drop-in audio platforms) so appealing and what helped it acquire millions of users in a matter of weeks despite an invite-only registration system.

\section{RESEARCH QUESTION \& METHODOLOGY}

Since Clubhouse uses an invite-only registration system (e.g. a person has to be invited to the platform by another user), the platform must clearly provide some value to the users, that they want to tell their friends about. We looked at a few different factors: type \& value of the discussed topics, interestingness of the speakers, an interesting media format and COVID-19 effect on the format.

As part of this research paper, different Clubhouse discussion topics were evaluated statistically. This was achieved using a reverse-engineered Clubhouse Application Programming Interface (API) provided by Harold Kim on Github (https://github.com/stypr/clubhouse-py).

To assess internet trends, Google Trends tools was used in combination with other social media websites (mainly Twitter and Reddit). Lastly, we used the app quite extensively ourselves to better understand how the platform operates. 


\section{DETERMINING THE MOST POPULAR TOPICS ON CLUBHOUSE}

Clubhouse allows users to follow or become members of so-called "Clubs", which are an interest-based collections of drop-in audio rooms. As followers, users can join and participate in the Club's rooms while Club members can also create a room within the Club. Using the reverse-engineered Clubhouse Application Programming Interface (API) provided by Harold Kim (https://github.com/stypr/clubhouse-py) the number of followers and members for all Clubhouse Clubs was programmatically counted and organized by Club's topic/subtopic. The twelve most popular subtopics on Clubhouse are presented in Table 1, followed by all 14 Clubhouse's topics in Table 2.

Table 1. Twelve most popular subtopics (out of 145) on Clubhouse by number of followers as of May $1^{\text {st }} 2021$

(full list accessible at https://clubhouse-topics.netlify.app/)

\begin{tabular}{lll}
\hline Topic & Number of followers & Number of members \\
\hline Entrepreneurship & $\mathbf{3 . 2 4 1 . 3 7 1}$ & 776.603 \\
Startups & $\mathbf{2 . 9 7 0 . 0 4 7}$ & 512.547 \\
The Future & $\mathbf{2 . 7 1 9 . 8 2 5}$ & 508.450 \\
Education & $\mathbf{2 . 1 2 8 . 5 0 4}$ & 529.823 \\
Networking & $\mathbf{2 . 0 8 8 . 7 1 3}$ & 717.343 \\
Mindfulness & $\mathbf{2 . 0 0 2 . 0 7 7}$ & 377.709 \\
Marketing & $\mathbf{1 . 5 8 6 . 2 8 6}$ & 280.110 \\
Meet People & $\mathbf{1 . 5 5 0 . 7 5 6}$ & 584.051 \\
Health & $\mathbf{1 . 4 0 8 . 6 6 2}$ & 400.105 \\
Advice & $\mathbf{1 . 1 2 5 . 0 9 1}$ & 375.497 \\
Crypto & $\mathbf{1 . 0 6 8 . 9 4 0}$ & 216.701 \\
Economics & $\mathbf{1 . 0 5 5 . 1 0 6}$ & 145.059 \\
\end{tabular}

Table 2. All topics on Clubhouse by number of followers as of May $1^{\text {st }} 2021$

\begin{tabular}{lll}
\hline Topic & Number of followers & Number of members \\
\hline Hustle & $\mathbf{9 . 6 1 7 . 8 3 6}$ & 2.595 .789 \\
Tech & $\mathbf{9 . 1 8 8 . 2 5 1}$ & 2.006 .251 \\
Knowledge & $\mathbf{7 . 1 7 0 . 9 3 2}$ & 1.804 .038 \\
Entertainment & $\mathbf{6 . 1 0 7 . 3 1 2}$ & 2.956 .458 \\
Wellness & $\mathbf{5 . 6 5 3 . 8 3 3}$ & 1.443 .407 \\
Arts & $\mathbf{4 . 1 5 7 . 6 6 3}$ & 1.539 .498 \\
World Affairs & $\mathbf{3 . 6 7 4 . 1 1 1}$ & 1.282 .113 \\
Hanging Out & $\mathbf{3 . 1 6 1 . 9 3 0}$ & 1.326 .444 \\
Life & $\mathbf{2 . 8 9 3 . 6 5 9}$ & 1.012 .527 \\
Identity & $\mathbf{2 . 2 3 9 . 4 9 6}$ & 1.138 .843 \\
Faith & $\mathbf{1 . 3 7 8 . 9 0 5}$ & 571.498 \\
Languages & $\mathbf{1 . 2 5 7 . 4 7 0}$ & 315.748 \\
Sports & $\mathbf{5 3 1 . 3 8 6}$ & 254.585 \\
Places & $\mathbf{4 5 3 . 5 1 5}$ & 532.355 \\
& & \\
\hline
\end{tabular}

As visible from Table 2, the three most popular topics on Clubhouse are all business oriented. This aligns with our personal experience in the app. There are many clubs focused on helping entrepreneurs from all kinds of industries, discussing different business, and marketing strategies. In our experience, speakers were usually real domain experts who were giving out free high-value advice to people who were just starting out. There were many instances of people taking notes of the speakers for the entire duration of the rooms. We also observed many people marketing their personal brands and offering services, using Clubhouse to create revenue. 
Clubhouse community highly values the so-called "Bio" (Biography) section of a user's profile. By providing some information about themselves, their interests and their Twitter / Instagram profile links, Clubhouse becomes a powerful networking tool. By our own observation, many people agreed to connect offline to continue talking about their mutual (professional) interests, many silent networking rooms (with no active speakers, only Bio readers) were also observed on Clubhouse.

\section{EFFECT OF CELEBRITIES ON CLUBHOUSE POPULARITY}

Influencer marketing is a well-proven marketing strategy (Jahnke, 2018). On Clubhouse, there were multiple occasions of high-profile executive (Elon Musk, Bill Gates, Mark Zuckerberg, etc.) and celebrity (Oprah, Drake, Jared Leto, Kevin Hart, MC Hammer, etc.) appearances. It is believed they joined on their own initiative (not paid for) to be interviewed by the moderators (normal users) and/or to answer questions from the public (Dee, 2021). Some consider Clubhouse a new way to interact with fans while the COVID-19 pandemic lasts. They consider the platform's media format to feel very authentic (Ali, 2021).

According to Google Trends, Google's Web Search trend analysis tool, Clubhouse's popularity on the Google Web Search peaked between $31^{\text {st }}$ of January and $6^{\text {th }}$ of February (Figure 1). However, $31^{\text {st }}$ of January is also the day Elon Musk, whose Tweets have proven to have effect on the stock market in the past (Pyeong Kang Kim, 2021), tweeted about speaking on Clubhouse later that evening.

While it is difficult to prove the exact cause and effect in this case, we will, however, conclude that it is very plausible that celebrity appearances made a significant impact on the platform's popularity.

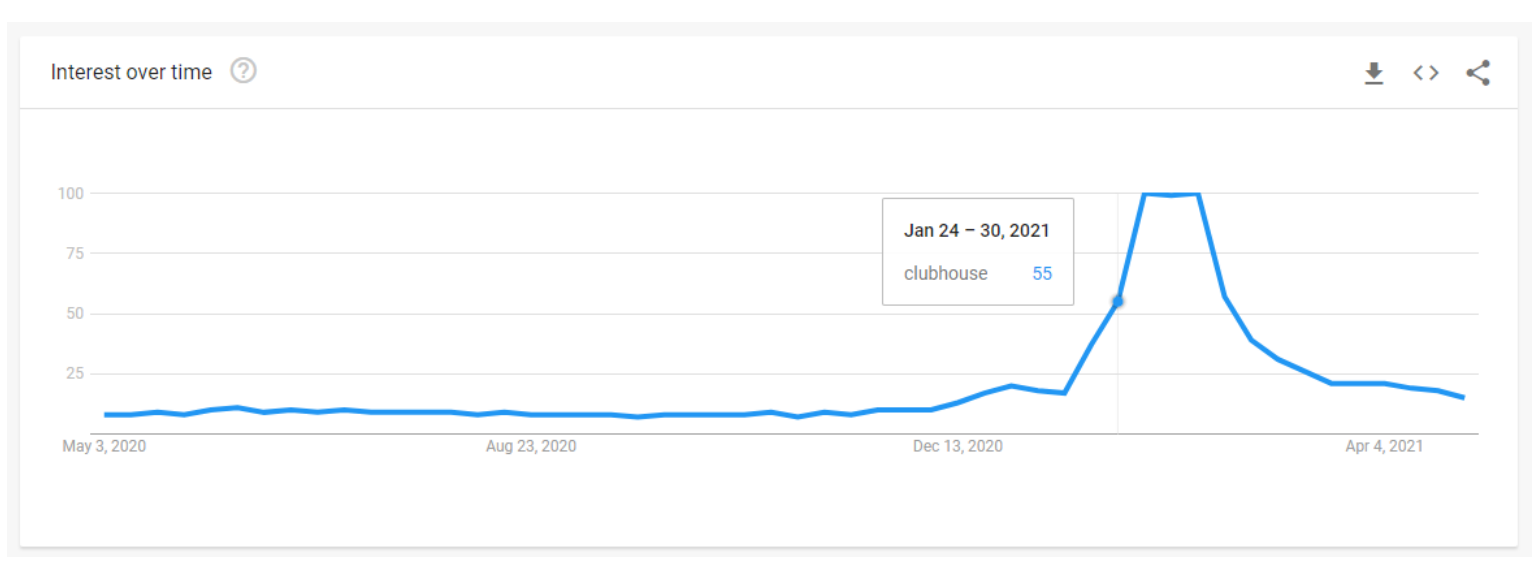

Figure 1. Google Search interest worldwide for term "clubhouse" for the past 12 months, $\%$ of max search volume

\section{OTHER UNICORN PLATFORMS}

To try and somewhat predict what Clubhouse's future will look like, we looked at another social media app that presented a new media format and saw incredible user growth - Snapchat. Snapchat acquired over 10 million users every 3 months in 2014 (Wagner, 2018). In 2016 Facebook introduced Instagram Stories that very closely resemble Snapchat's "Stories" media format, followed by stories on Facebook and WhatsApp. In the following years, Snapchat's growth almost stopped and maxed out at around 190 million daily active users in 2019. For Facebook, the introduction of Instagram Stories proved to be a big success with over 500 million daily active users in 2019 (Figure 2). Over a period of 3 years from ' 16 to '19, the two platforms coexisted. The same could happen to Clubhouse. 


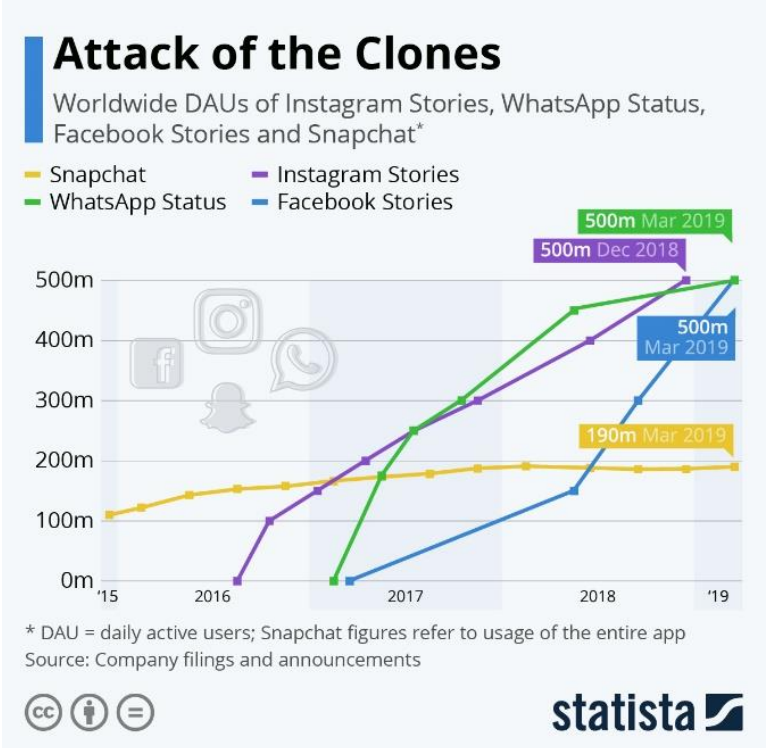

Figure 2. Number of daily active users on Snapchat, Instagram Stories, Facebook Stories and WhatsApp Status, 2015 - 2019, acquired from (Richter, 2020)

\section{CONCLUSIONS}

Using the data acquired through the Clubhouse API, we were able to conclude that most discussions and people's interests on Clubhouse are business oriented. By our own experience on the platform, we were able to confirm this as well. We can also conclude that some people are/were using Clubhouse as a learning platform, much like a webinar, where they can acquire high-value domain knowledge by listening in on expert discussions about a subject entirely free of charge. The popularity of "Networking" and "Meet new people" subtopics also signifies that Clubhouse is a (business) networking platform. People creating revenue with their personal brand on Clubhouse were also observed.

Many celebrities and high-profile executives also appeared on Clubhouse. We concluded that it is very plausible that their appearances had a significant impact on the platform's popularity. By reading the interviews, we were able to conclude that for celebrities, Clubhouse presents an interesting new media format and a new way to interact with fans. They find this new media format to be very authentic. This stands true in our own experience as well.

In conclusion, current Clubhouse's most popular topics are mainly business-oriented. However, that could quickly change, because the platform's format feels very authentic. This has already been noticed by the entertainment industry and might be noticed by even more people when the same core features are brought over to platforms such as Instagram, Twitter and Facebook. Recently, Clubhouse has been criticized for the lack of privacy options, especially because all user's contacts have to be uploaded to the app's servers in order to even use the app (Morrison, 2021). It remains to be seen whether Clubhouse will remain as popular once the COVID-19 pandemic ends and the competition catches up. 


\section{REFERENCES}

Ali, R. (2021, February 22). 'Unfiltered access': Why Kevin Hart, Elon Musk, more celebs are connecting with fans on Clubhouse. Retrieved from usatoday: https://eu.usatoday.com/story/entertainment/celebrities/2021/02/22/clubhouseapp-explainer-celebrities-how-to-get-unfiltered-access/6780989002/

Culliford, E. (2021, April 18). Clubhouse closes new round of funding that would value app at \$4 billion -source. Retrieved from Clubhouse closes new round of funding that would value app at $\$ 4$ billion -source: https://www.reuters.com/technology/clubhouse-closes-new-round-funding-that-would-value-app-4-billion-source2021-04-18/

Daniel Pyeong Kang Kim, J. L. (2021). Elon Musk's Twitter and Its Correlation with Tesla's Stock. International Journal of Data Science and Analysis, 7(1), 13-19.

Dee, J. (2021). Screenrant. Retrieved from https://screenrant.com/celebrities-entertainers-comedians-follow-onclubhouse-apple-social-media/

Jahnke, M. (2018). Influencer Marketing (1 ed.). Wiesbaden: Springer Gabler. doi:https://doi.org/10.1007/978-3-65820854-7

John, A.-A. (2021, April 8). Which Clubhouse Clone Is Most Likely to Succeed? Retrieved from Make Use Of: https://www.makeuseof.com/which-clubhouse-clone-is-most-likely-to-succeed/

Morrison, S. (2021, February 22). Vox Recode. Retrieved from You've been invited to Clubhouse. Your privacy hasn't.: https://www.vox.com/recode/22278601/clubhouse-invite-privacy-contacts-app

Richter, F. (2020, August 7). Statista.com. Retrieved from Snapchat vs Facebook: Attack of the Clones: https://www.statista.com/chart/10558/daus-instagram-stories-whatsapp-status-snapchat/

Statista. (2021, April 30). Number of weekly active Clubhouse users from April 2020 to February 2021. Retrieved from Statista: https://www.statista.com/statistics/1199871/number-of-clubhouse-users/

Wagner, K. (2018, August 8). 'Stories' was Instagram's smartest move yet. Retrieved from Vox Recode: https://www.vox.com/2018/8/8/17641256/instagram-stories-kevin-systrom-facebook-snapchat 